\title{
EL PENSAMIENTO ECONÓMICO-SOCIAL DE RODRIGO FACIO ${ }^{1}$
}

\section{THE ECONOMIC AND SOCIAL THOUGHT OF RODRIGO FACIO}

\author{
José Luis Vega Carballo*
}

RESUMEN

Este artículo recoge los aportes principales de esta señera figura del reformismo socialdemócrata de los años cuarenta y cincuenta del siglo pasado, así como de aspectos sociopolíticos muy relevantes de su obra y su accionar, sobre todo dentro del ámbito político y del desarrollo del pensamiento estratégico en materia económica y de planificación democrática. Asimismo, destaca la importancia de Facio como aportador, quizás pionero en nuestro medio y más allá, en materia de lo que luego se llamó la teoría de la dependencia. Al final, llama a retomar el camino abierto por Facio sobre la problemática de la independencia y el desarrollo nacionales, en momentos donde el avance del neoliberalismo parece haber cerrado las rutas hacia ambos.

PALABRAS CLAVE: RODRIGO FACIO BRENES * PENSAMIENTO ECONÓMICO * PLANIFICACIÓN SOCIAL * TEORÍA POLÍTICA * DESARROLLO INTEGRADO

\section{ABSTRACT}

This article includes the main contributions of this landmark figure of social reformism of the forties and fifties of the last century, as well as very relevant sociopolitical aspects of his work and his actions, especially in the political area and the development of strategic thinking in economic and democratic planning. It emphasizes the importance of Facio as contributor, perhaps a pioneer in our country and beyond, in terms of what would later be called the theory of dependency. Finally, it calls to retake the lead of Facio on the problematic of national independence and development, in times where the advance of neoliberalism seems to have closed the routes to both.

KEYWORDS: RODRIGO FACIO BRENES * ECONOMIC THOUGHT * SOCIAL PLANNING * POLITIC THEORY * INTEGRATED DEVELOPMENT

1 Texto de una exposición realizada el 7 de junio de 2011, en un acto conmemorativo organizado en el auditorio de la Escuela de Estudios Generales por la Vicerrectoría de Investigación de la Universidad de Costa Rica (UCR) y familiares del exrector Facio, al cumplirse medio siglo de su fallecimiento.

* $\quad$ Catedrático de Sociología de la Universidad de Costa Rica (UCR).

jlvega@ice.co.cr 
I

Rodrigo Facio Brenes fue abogado y a la vez un economista autodidacta, quizás el más sobresaliente de su generación, un distinguido profesor de doctrinas económicas y banquero público. No fue un político tradicional ni profesional, pero su influencia intelectual en la política a partir de 1940 y en la Asamblea Constituyente de 1949, fue notable, imperecedera y lo perfiló como un visionario estadista en quien muchos pensaron para ocupar la presidencia de la República. Fue un pensador económico que podríamos ubicar perfectamente en el terreno de la economía política interesada por un lado, en las interacciones entre la producción y la distribución como fenómenos colectivos y por otro lado, el Estado, el poder político y el estilo de desarrollo. No fue, por tanto, un economista tecnocrático o un econometrista al estilo de la mayoría de los actuales profesionales de esa disciplina. Al contrario de ellos, no se interesó por copiar recetas, ni por seguir modas y recomendaciones de algún Organismo Financiero Internacional (OFI) como sucede actualmente. Tampoco le importó vender sus servicios como consultor o asesor o bien, como abogado de un prestigioso bufete, a los dueños del capital nacional o foráneo ni por hacerles modelos, cálculos financieros o balances contables con los cuales pudieran afinar sus maquinarias de extraer excedentes y acrecentar fortunas en la ruleta de los mercados.

Fue un pensador muy original entregado a buscar un mejor destino para su pueblo, que utilizó la teoría económica de su tiempo sin apego a dogma alguno ni subordinación a intereses privados. Se esmeró más por ser un hombre público que un aséptico profesional. Tampoco fue partidario de los extremismos. Como verdadero libre-pensador evitó los dogmatismos, los rígidos y abstractos esquemas de análisis de la modelística económica neoclásica, mostrando además un especial eclecticismo teórico-metodológico al tratar por años de conciliar liberalismo y socialismo desde posiciones intermedias $y$ no extremas en uno $u$ otro sentido; lo cual le acerca, con su concepto de "liberalismo constructivo" lanzado en 1941, a la corriente contemporánea del "social-liberalismo" asumida por muchos socialdemócratas y exmarxistas europeos de la nueva izquierda.

Facio no hizo teoría económica por la teoría misma, sino que basándose en los clásicos del liberalismo inglés, en Marx y en autores heterodoxos como John Maynard Keynes, trató por una parte, de aprovechar lo mejor de los aportes de todas esas vertientes sin encerrarse nunca en ninguna y por otra, de manejar conceptos y teorías "heurísticamente", a saber, como herramientas útiles de investigación de nuestra realidad económico-social y política, y nada más. Lo hizo, eso sí, con una visión integral, estructural e histórica que lo coloca entre los precursores de la teoría del desarrollo que en el medio latinoamericano de la economía y las ciencias sociales surgiría como gran tema del momento en las décadas de 1950 y 1960.

Si aplicó la teoría de modo flexible y creativo a la comprensión de nuestra realidad nacional, no fue por mera ilustración ni para sentar doctrina o dogma, sino para extraer fórmulas creativas para su refundación sobre bases de mayor bienestar y justicia social para las grandes mayorías ciudadanas; de nuevo procedió contrariamente a muchos de nuestros economistas neoliberales que se desvelan solo por apoyar la gestión lucrativa de la clase capitalista y de los inversionistas extranjeros, así como por hacer formulaciones de política económica y pública en función de sus estrechos intereses especulativos o bien, según las prescripciones o "enlatados" de los OFIs.

En síntesis: Facio fue un pensador original que usó, pero no se dejó usar por la teoría económica a modo de una camisa de fuerza - tal como lo vemos hoy en muchos exponentes del llamado "pensamiento único" de los OFIs, promotores del neoliberalismo y el globalismo. No se puso al servicio de ninguna ideología. La teoría, que Facio bien dominaba, fue para él un gran instrumento para comprender tanto el estilo, los problemas y desafíos del desarrollo de Costa Rica y de Latinoamérica en el sistemamundo, como para orientarse $y$ fundamentar sus tesis a la hora de hacer innovadoras propuestas políticas y programáticas, algo que se convirtió 
en costumbre desde que fue miembro fundador del Centro para el Estudio de los Problemas Nacionales allá por 1940. Combinó siempre teoría e investigación con la solución de problemas, para lo cual siempre mantuvo respecto a la economía una visión de conjunto o macro, histórico-estructural y de largo plazo. Primeramente, la analizaba como un sistema o un todo contradictorio, sometido a los rigores $y$ hasta las violencias del ciclo económico cuando las fuerzas y leyes del mercado se dejaban por la libre, para pasar luego a examinarla sectorialmente y proponer fórmulas más concretas $y$ afinadas de fomentar el bienestar general $y$ el desarrollo. Tuvo, pues, una concepción que podría llamarse un "humanismo socialista" de su propio cuño: los mercados podían y debían ser sometidos mediante la planificación a objetivos superiores tanto de racionalidad como de bienestar y justicia, para lo cual era necesario rectificar los errores y excesos del liberalismo, hoy diríamos del libre comercio y la especulación financiera globalizada. Pero, en esto como en cualquier otra materia de intervención $y$ manejo de política económica, era indispensable evitar el pensamiento cerrado y ortodoxo. Como lo afirmó en una polémica que sostuvo con un defensor a ultranza de la banca privada a finales de agosto de 1949:

En esta materia de política económica general yo, como costarricense, no puedo ser un extremista ni un radical... Yo en esto soy pragmático, práctico, valga decir, costarricense. No quiero ni puedo ser ideólogo ni teorizante (Diario de Costa Rica, 25 de agosto de 1949).

Por todo lo antedicho, Facio fue y sigue siendo hasta hoy, la máxima figura intelectual y política del reformismo progresista, una corriente político-ideológica que gusta de jugar en el medio campo y que aún intenta -quizás en vano- darle "rostro humano" al capitalismo para avanzar hacia un socialismo moderado, liberal y de mercado "a la tica". Aunque no le hubiera gustado el término, fue quizás el primer gran ideólogo, aún no superado del progresismo nacional hasta la derrota $y$ retroceso de sus ímpetus renovadores por la imposición del programa neoliberal de ajuste estructural de los años de 1980-90 al presente. En este sentido, pensó en la conveniencia de adoptar una especie de economía "mixta" como base de la Segunda República, donde las clases medias y trabajadoras fueran poco a poco mejorando su condición y abriendo más oportunidades de bienestar y vida a su favor, mediante concesiones arrancadas a los dueños del capital; tarea para la cual se requería de su parte el expediente del partido político ideológico y permanente, pluralista y poli-clasista, así como, un reforzamiento institucional de la democracia liberal. Si hubiera podido llegar a verlo, le hubiera sorprendido y dolido mucho el viraje contra-reformista de corte neoliberal de esos años, aún en marcha.

\section{II}

Pero Facio no fue solo un pensador o filósofo en materia de teoría y política económica, mucho menos un académico metido en torre de marfil. Ocupó destacadas posiciones en el campo de la enseñanza de la economía $y$ de su manejo. Entre otras, fue profesor de Moneda, Crédito y Banca en la Escuela de Derecho de la recién fundada Universidad de Costa Rica (UCR) en 1942; la misma materia dictó en la Escuela de Ciencias Económicas y Sociales junto a Teoría General de la Ocupación y Doctrinas Económicas. Luego se desempeñó como vicedecano y decano de la misma Escuela entre los años de 1947 a 1952, para convertirse este año en rector de la UCR hasta su renuncia al cargo en enero de 1961, motivada por su deseo de ocupar posiciones en el campo internacional y para dedicarse a investigar y escribir con más holgura sobre temas de interés. Más fue este el mismo año de su sorpresivo fallecimiento y el final de su brillante carrera. En suspenso quedó su obra "Latinoamérica en la Encrucijada", así como, varios escritos tendientes a desarrollar más el gran tema que lo apasionó en los años de 1950: la planificación económica en régimen democrático.

Fuera del ámbito académico fue nombrado en 1948 por la Junta Fundadora de la Segunda República como miembro del Comité Asesor del Ministerio de Economía y Hacienda 
$y$ en 1949, miembro de la Comisión Redactora de la Ley Orgánica del Banco Central de Costa Rica. Luego, integrará la Junta Directiva del Banco Central entre 1950 y 1960, entre otros cargos ligados al manejo de la banca pública y la defensa de su autonomía frente a injerencias políticas. Como bien sabemos, una banca nacionalizada (o más bien estatizada) por la Junta de Gobierno figuerista en 1948 y a la cual defendió brillantemente en muchas ocasiones, ante ataques de las derechas conservadoras, en especial del banquero Jaime Solera Bennett, con quien mucho polemizó.

Supo comunicar bien su pensamiento con estilo muy claro, llano y ameno. Sus publicaciones de orden económico son numerosas, en periódicos, revistas, folletos y libros tanto de nuestro país como del extranjero. Solo recordemos cuando en 1947, el Fondo de la Cultura Económica de México publicó su obra "La Moneda y la Banca Central de Costa Rica", anteriormente presentada exitosamente en un concurso universitario. Hoy contamos con la publicación de sus obras completas en tres tomos por la Editorial Costa Rica.

Como joven diputado constituyente en 1949, defendió ardorosa y brillantemente la nacionalización bancaria, el proyecto progresista presentando por la Junta y fue la figura responsable de balancear el texto aprobado de nueva Constitución Política entre liberalismo y dirigismo socialdemócrata, permitiendo que, según las circunstancias, el péndulo de las élites se moviera hacia un lado u otro del espectro en materia de toma de decisiones $y$ evitando, por lo menos hasta que se aprobaron los tratados de libre comercio actuales (en especial el pactado con Estados Unidos -EEUU), que la Constitución perdiera su equilibrio $y$ fuera sobrepasada $y$ violentada por camisas de fuerzas a gusto de los intereses del gran capital local o internacional; ya que los tratados en el caso de Costa Rica funcionan con rango superior al de nuestras leyes internas y operan como verdaderas "constituciones económicas" apoyadas en la Convención de Viena y la enorme presión de los OFIs y los gobiernos de las grandes potencia capitalistas que dominan la globalización.
El trabajo de Facio como economista lo combinó con el de educador en dos escenarios: la clase en el aula y su labor destacada como Secretario General de la Universidad (1946), Decano de la Facultad de Ciencias Económicas y Sociales (1947 a 1952) y rector de la institución (1952 a 1961).

III

Los escritos económicos de Facio demuestran que bebió de muy variadas fuentes. Fue muy influido por los planteamientos reformistas del expresidente González Flores, el anti-imperialismo de Haya de la Torre y José Carlos Mariátegui (espacio-tiempo histórico: especificidad de América Latina y sus problemas: reduccionismo nacionalista) y conocía bien, las tesis de Lenín, Hilferding y Hobson sobre el imperialismo. Estudió y manejó a fondo a Marx con su crítica a los teóricos clásicos del capitalismo liberal, así como, las tesis heterodoxas de John Maynard Keynes en materia de crisis y política anti-cíclica, sin olvidar a los estrategas del "New Deal" de Franklin D. Roosevelt $y$ a los aportes de los economistas, como el austriaco Joseph Schumpeter y el sueco Gunnar Myrdal. También fue atraído por el nacionalismo de la legendaria "Liga Cívica" de finales de los años 20, los planteamientos de Omar Dengo y del afamado Dr. Ricardo Moreno Cañas; $y$ lo influyó sobremanera el reformismo colombiano recibido a través del embajador en Costa Rica de ese país, el Dr. Plinio Mendoza Neira. En Sociología Política, área incipiente en su época donde Facio incursionó con mucho interés y acierto como lo demuestra en casi todos sus estudios, las mayores influencias provinieron de Harold Laski, Walter Lippman y Robert McIver.

Lo más notable es, ya en su tempranero Estudio sobre Economía Costarricense, que se anticipó por 10-15 años al pensamiento económico de la otrora prestigiosa Comisión Económica para América Latina de las Naciones Unidas (CEPAL) y de su ilustre director, el economista argentino Raúl Prebisch. Lo observamos cuando apenas teniendo 24 años, en el año en 1941, presentó el Estudio como tesis de licenciatura en Derecho para la UCR, obra publicada al 
año siguiente por la Editorial Surco del famoso ateneo reformista "Centro para el Estudio de los Problemas Nacionales", del cual fue indiscutible líder intelectual hasta su disolución en 1945 para forjar el Partido Social Demócrata. En esta seminal obra, Facio anticipó y aplicó varias nociones y esquemas analíticos que anticiparon el pensamiento y el enfoque de los problemas del desarrollo latinoamericano de los círculos de la CEPAL $y$ de Prebisch, $y$ que posteriormente terminaron de ser desarrolladas bajo el signo de la "teoría de la dependencia y del desarrollo" de la sociología latinoamericana de los años de 1960 y 1970. Veamos:

a) La noción "de dependencia externa" como dimensión compartida por el neocolonialismo y el imperialismo -términos que a Facio no le daba miedo utilizar - la usó como variable estructural para explicar la formación de la sociedad $y$ el Estado costarricenses en el contexto de la mundialización capitalista anterior a la segunda guerra mundial, al estudiar los efectos de la penetración del capital inglés y luego del norteamericano, aunque claramente esa dependencia tuvo sus antecedentes absolutistas y mercantilistas en el modelo de la colonia española.

b) La noción de "subdesarrollo" afloró en el momento de estudiar el atraso del sector de las subsistencias y el influjo de la economía mini-fundiaria o pequeñocampesina de los siglos XVII y XIX como abastecedora del mercado interno $y$ subordinada a la externa, dando a entender que este subdesarrollo era la otra cara del desarrollo inducido por las relaciones con, y la dinámica de, el imperialismo en sus varias modalidades, unas veces estimulantes, otras absorbentes.

c) Y en conexión con la investigación de esa dinámica dualista, fue cuando surgió la noción de "economía de enclave", esbozada en sus agudos análisis del sector bananero, bajo dominio del capital estadounidense $y$ expuesto como modelo de injerencia y explotación distinto al inglés, que según Facio, apoyó un desarrollo autogenerado de capitales $y$ fuerzas productivas alrededor del café y otros cultivos en el siglo XIX y más adelante, cuando apareció una incipiente pequeña industria urbana local; es decir, lo que ahora conocemos como un "desarrollo desde adentro" y un "desarrollo desde abajo" (o socialmente inclusivo) dentro de la dependencia global externa, que alentó la formación de una clase media, la cual fue primero rural y posteriormente urbana, ya entrado el siglo xx en el lapso de entreguerras mundiales; lo que fue visto por Facio como impulsor del progreso y el crecimiento económico nacional debido a la manera como fomentó procesos de movilidad social vertical y ascendente, a partir de las clases trabajadoras y campesinas.

d) Aunque a inicios de la década de 1950, utilizó varias veces el esquema "centroperiferia" para analizar la relación de la URSS con sus satélites europeos, lo cierto es que en el Estudio aparece ya implícito $y$ luego lo esgrime de manera explícita y más amplia, cuando trata de entender el dominio de las economías capitalistas occidentales sobre las más débiles y desarrolladas; la mayoría salidas de experiencias coloniales anteriores a la segunda guerra mundial y por tanto, ahora en la segunda posguerra mundial, sometidas a los embates $y$ distorsiones del neocolonialismo y el imperialismo de las potencias capitalistas, principalmente -en nuestro caso- de los EeuU.

\section{IV}

Para 1945, Facio ha llegado a la conclusión de que, por el camino del liberalismo económico, el país no debía seguir transitando. Había que "rectificarlo"; pero la opción no era el socialismo marxista ni solo las "garantías sociales" o el Código de Trabajo, a las que según él faltaba buen sustento económico. Conviene en este caso citarlo: 
Apoyamos las Garantías Sociales, reconociéndoles el valor real que tienen: ordenamiento y complementación de leyes salariales gradualmente emitidas en los últimos veinte años, relativo fortalecimiento de los principios en que ellas se inspiran por su elevación a texto constitucional, $y$ oportunidad para la difusión de los nuevos conceptos de la democracia social en nuestro medio.

\section{Y agregaba:}

Exigimos medidas de carácter complementarios, económicas, fiscales y políticas, que tiendan a darles fundamento positivo $\mathrm{u}$ oportunidad para su real aplicación o goce (El Centro ante las Garantías Sociales. Imprenta Borrasé, 1943: 13).

En otro escrito de la época, insiste en su apoyo al aspecto progresista de las Garantías Sociales y el Código de Trabajo, pero hace hincapié en la necesidad de aprobar medidas complementarias, económicas y políticas, que las reforzaran permitiendo ampliarlas en el futuro. Decía:

En un país como el nuestro, la justicia social solo puede lograrse por la doble vía de la legislación social que garantice jurídicamente a las clases humildes su derecho a la vida, $y$ de la organización económica que garantice materialmente, en términos de una producción incrementada y diversificada, que las clases humildes podrán efectivamente ejercer ese derecho (Revista Surco 40. Octubre 1943: 26 y siguientes).

Para Facio, lo más importante para el país era avanzar hacia el establecimiento de la "función social" de la propiedad privada (afirmado en el plano constitucional en 1949) junto a una redistribución progresiva del ingreso (función de "justicia social"), con lo cual se podría estimular la formación de una extensa nueva clase media urbana que, unida a la rural desarrollada por el café, viniera a fortalecer el régimen democrático y la redistribución del ingreso y el poder. Al respecto, se mostró como un auténtico defensor de la clase media $y$ la movilidad social, factores capaces de ampliar mercado interno y dinamizar la estructura social interna para de ese modo irle dando, entre otras cosas, mejor sostén a la reforma social del caldero-comunismo de los años 40. Pero para eso se requería algo más; a saber:

1. Intervención estatal selectiva y comedida, una especie de "liberalismo constructivo" o democracia social que sirviera de guía para forjar, como se diría una "economía de mercado"; pero no una "sociedad de mercado" al estilo del neoliberalismo actual, con una clase capitalista gobernante $y$ excluyente, producto del libre mercado y los procesos incontrolados de concentración y centralización de la riqueza en pocas manos; muchísimo menos para darle aliento a un modelo de Estado liberal gendarme que funcione como gran palanca de los negocios privados e intermediario de los inversionistas extranjeros con el consiguiente refuerzo de la relación de la dependencia neocolonial, como lo plantea la doctrina del Banco Mundial llamada "neo-institucionalismo" en estos días cuando los OFIs impulsan una segunda generación de reformas de ajuste estructural o "Consenso de Washington" con el fin de acabar con los restos del Estado de Bienestar en los centros y periferias del sistema-mundo capitalista.

2. Las teorías económicas serían solamente guías o paradigmas, simples medios pragmáticos y flexibles de conseguir ese fin. Facio afirmaba que, con ese intervencionismo estatal mesurado o dirigismo bien orientado $y$ planificado, se superarían muchos de las limitaciones de la democracia y del subdesarrollo:

Habremos así abandonado el liberalismo económico, pero no destruyéndolo con una estatización de carácter totalitario, sino 
superándolo mediante un régimen mixto de organizaciones autónomas cooperativas, $y$ de intervención del Estado a través de sus "Servicios" sobre las fuerzas económicas oligarcas o monopolistas (Revista Surco 52. Febrero 1945: 23).

3. Hablaba asimismo de un "Estado Inteligente" en la Asamblea Constituyente de 1949, como eje de la estrategia renovadora, capaz de ponerle coto al librecambismo manchesteriano. Afirmaba:

Si ha de garantizársele al ciudadano medio, al hombre de la calle todos esos recursos y seguridades, pues ello tendrá que ser sacrificio de un Estado liberal, neutral entre los grandes problemas sociales, ello tendrá que ser con abandono del ejercicio libérrimo y absoluto de la propiedad particular, ello tendrá que ser mediante la intervención inteligente del Estado para distribuir mejor la riqueza nacional, limitando los abusos y las injusticias a que el absolutismo de la propiedad privada sin límites da lugar (Actas de la Asamblea Nacional Constituyente de 1949. Imprenta Nacional, 1951, tomo I, sesión 50 del 6 de abril de 1949).

La visión de Facio en esta materia no termina ahí, en una clave internista. Siempre vio la economía nacional como conjunto inserto globalmente y por esa misma razón, la define como suma de sectores nacidos en distintos tiempos y espacios, aspecto que debe tenerse en cuenta para efectos de política económica y pública. Por eso, divide a la economía nacional en al menos "tres zonas", a cada cual debiendo darle la política económica trato particular en función de las especificidades regionales adquiridas mediante este patrón de "crecimiento de agregación por sectores", sin apegarse (como ahora sucede) a decisiones que son centralistas, abstractas y universales, como las impuestas en estos tiempos que corren al calor de un neoliberalismo eliminador de las diferencias locales y regionales, movido por un compulsivo afán totalitario y autoritario de estandarizar la economía y su manejo dentro de los cánones del globalismo y el "pensamiento único". He aquí el planteamiento de zonificación o regionalización de Facio:

a) 1era. zona. Actividades monopolizadas donde el sujeto es el capital extranjero: fuerzas hidroeléctricas, navegación aérea, ferrocarril al Atlántico, etc. Aquî recomienda la expropiación y puesta de los servicios y de empresas agroindustriales exportadoras, todo bajo administración pública para brindarlos al costo o explotarlos con vistas al interés nacional y público, no como enclaves extranjeros (banano, abacá y demás frutos de exportación).

b) 2nda. zona. Actividades semi-monopolizadas: transformación industrial del café y de la caña de azúcar, comercio de granos, etc. Aquí plantea un control social y público directo, o mejor el indirecto por medio de organizaciones cooperativas a las cuales Facio siempre vio como el germen de lo que ahora se ha llamado un "sector de economía social".

c) 3era. zona. Actividades sometidas al mercado libre y competitivo: producción agrícola o industrial a cargo de pequeños propietarios. Aquí se inclinaba por el cooperativismo de nuevo, con fuerte apoyo estatal en combinación con controles antiespeculativos y antimonopolio, ojalá a cargo de "instituciones autónomas públicas”, o sea, descentralizadas aunque coordinadas y planificadas como conjunto armónico según lo planteará posteriormente. Nótese aquî el uso inédito del concepto ya en el año 1943, el cual luego y por su esfuerzo quedaría plasmado en la Constitución Política de 1949 (ver su "Programa Costarricense de Rectificaciones Económicas" en la Revista Surco 38-39. Julio/septiembre de 1943). 
Es interesante lo que Facio dice sobre cómo sería la dinámica estatal y socio-productiva en cada una de esas zonas que fija en el "Programa":

Dentro de cada una de esas zonas y en relación con el grado de su organización o control, cabría ir aplicando una legislación social orgánica llamada esencialmente a levantar el nivel de vida del asalariado $y$, por allí, a hacer más productivo su trabajo.

Y añade algo aún más interesante e innovador:

Tenemos, en consecuencia, dos clases de instituciones $\mathrm{u}$ organizaciones económicas llamadas a sustituir o a controlar, según el caso, la gestión del capitalismo extranjero y nacional: las instituciones autónomas del Estado — que llamaremos Servicios...-y las cooperativas.

En 1943, en el citado "Programa de Rectificaciones", las instituciones autónomas del Estado son entonces definidas esencialmente como "Servicios Públicos" y propone cuatro tipos principales, los que se encargarían de ejecutar dicho programa: "Servicios de administración" (encargados de negocios o empresas expropiadas o sustraídas de la propiedad particular capitalista), "Servicios de control e inspección" (para supervisar actividades o empresas semi-monopolistas privadas), "Servicios de protección, estímulo y organización" (con la función de apoyar a las medianas y pequeñas empresas. Hoy diríamos "pymes") que trabajan bajo competencia de mercado, en especial cooperativas y "Servicios de contratación pública internacional" (organizados como oficinas dedicadas a estudiar y proponer proyectos a contratar con empresas extranjeras, administrar tratados comerciales y económicos internacionales, etc.).

En Surco (Nro. 38 de agosto de 1943) habla de que este programa de rectificaciones económicas puede ser la guía para llevarnos a "poner el país a tono con las tendencias internacionales, iniciando lo que podría llamarse un socialismo costarricense". Es decir, "un plan de organización económico-social" centrado en reformas audaces y profundas que no impliquen una "estatización autoritaria" ni "desechar nuestra tradición política liberal y democrática", sino "fortalecer las bases sociales a nuestro régimen democrático", "resolver los problemas con nuestras propias fuerzas $y$ de acuerdo con los intereses $y$ los sentimientos de las mayorías sociales" y "terminar con las causas de la miseria económica y el desequilibrio social que día tras día se agudizan y tornan más graves para el Pueblo y la República”.

Para impulsar ese modelo de "socialismo a la tica", para Facio es indispensable tomar el tema del desarrollo, poniendo énfasis no solo en la formación del capital físico y monetario, sino por sobre todo en la formación y mejoramiento del recurso humano, especialmente mediante la educación y la salud. No es posible extenderse mucho aquí sobre este punto que es más del resorte de la Sociología Económica y que raya con el tema de lo que el ilustre profesor de Sociología José Medina Echavarría llamó "los factores sociales del desarrollo". Baste anotar que en un discurso de cierre del curso lectivo, el 26 de diciembre de 1958, luego de afirmar que "la educación es claro requisito del mantenimiento y el desenvolvimiento de la propia democracia y, al mismo tiempo, del mejoramiento de las condiciones materiales de vida", pasa a plantear la siguiente tesis fundamental: para el desarrollo es "condición obligada que los recursos humanos son el factor decisivo para el progreso económico, y que la educación, muy lejos de ser lujo y ni siquiera un gasto corriente de consumo, es una de las formas más eficaces y reproductivas de inversión o capitalización". Culmina afirmando que "caemos así en la cuenta — sin sorpresa por cierto- de que el hombre es lo primero, no solo espiritual y moralmente, sino también desde el ángulo puramente material. La economía se agrega a la religión y la ética para confirmarlo como el punto de arranque y el punto de llegada de todo en este mundo".

En cuanto a la dimensión de la salud es enfático al decir " $y$, debemos agregar, inversión en salud. Pues el mejor financiado y equipado programa de industrialización se frustrará, 
sino hay un pueblo sano que lo respalde, $y$, en cantidades adecuadas, hombres de ciencia, especialistas, profesionales, técnicos y operarios calificados para llevarlo adelante". Puntos de vista estos que no han perdido su relevancia en el escenario contemporáneo donde gracias al neoliberalismo de moda, pero ya afortunadamente con signos de reculada $y$ desbande, los servicios públicos de educación y salud se han ido deteriorando a pasos agigantados en cuanto a cobertura y calidad de la prestación, lo que ha puesto en severo peligro uno de los baluartes del progresismo nacional $y$ del reformismo desarrollista sobre los que se asentó la Segunda República que Facio tanto contribuyó a construir. Esperemos que el país dé un giro pronto hacia una refundación del Estado de Bienestar bajo la consigna — que estamos seguros Facio suscribiría en aras del socialismo costarricense con que soñó- de no insistir en la fórmula neoliberal de "menos Estado para más mercado", sino en la de "más y mejor Estado de Bienestar"; dejando que el mercado haga lo suyo hasta donde pueda hacerlo sin atacar a la justicia y la equidad sociales, y menos a la democracia como lo ha hecho bajo la fórmula de que hay mucha ingobernabilidad $y$ que se necesita una "tiranía en democracia", es decir, una dictadura reaccionaria, autocrática y camuflada de régimen constitucional o Estado de Derecho, según el planteamiento de un conocido expresidente y premio Nobel de la Paz.

\section{V}

El problema del desequilibrio social ("sociedad de mercado" con predominio de los más fuertes y los "ganadores" en la competencia) y de los atentados del liberalismo individualista contra la democracia (régimen de "tiranía plutocrática en democracia”), no solo lo ubicó a Facio en el plano local, sino también en el internacional $y$ lo hizo con claridad $y$ contundencia, denunciando los males del imperialismo $y$ el neocolonialismo de las grandes potencias del capitalismo metropolitano o central, con sus abusos e injerencias distorsionantes en los países de la periferia. Sobre todo en sus últimos años, a finales de la década de 1950, Facio señalaba que los desajustes del "mundo liberal" deben rectificarse allí también, precisamente donde "... las naciones económicamente fuertes tienden a convertir a las débiles en simples productoras de materias primas $y$ frutos alimenticios" ("Planificación Económica en Régimen Democrático", separata de la Revista de Ciencias Sociales de la UCR, septiembre de 1959). En una conferencia dictada en octubre de 1957, en un ciclo universitario sobre "La Filosofía del Siglo xx", donde aborda el tema Clasicismo y Marxis$m o$, insiste en ciertos aspectos positivos del liberalismo, pero se refiere ante todo al "liberalismo del espíritu" y a esferas como "independencia personal, garantías frente al poder político, tolerancia religiosa, libertad de conciencia, libertad de pensamiento científico y filosófico, libre manifestación de las ideas, etc.”. Pero de inmediato agrega algo que no aceptaría de buena gana el liberalismo individualista y librecambista anglosajón: "junto con la adopción de la igualdad y la fraternidad - por lo menos en el pensamiento enciclopedista francés- como principios normativos de la organización social". De seguido proclama, en la misma conferencia, la necesidad de corregir los malos resultados del liberalismo económico de origen manchesteriano advirtiendo que, si no se emprende un programa de rectificaciones, entonces:

... la experiencia nos ofrecerá un espectáculo de desajustes económicos y conflictos sociales: ciclos económicos con sus terribles fases de depresión; concentración de los capitales en grandes corporaciones con su secuela de abusos contra las firmas pequeñas, el obrero y el consumidor; surgimiento de la competencia limitada o monopolística; desocupación obrera; pugnas industriales con sus puntos culminantes de la huelga $y$ el paro; $y$ todo esto sin contar los problemas de la economía mundial $y$ el creciente divorcio del nivel de vida de los países industriales y los subdesarrollados (Conferencia publicada en la Revista de la Universidad de Costa Rica 16. Enero 1958: 97-124).

Cabe preguntarse en este punto: ¿dado el escenario actual gobernado por los dictados 
del capitalismo neoliberal y global, $y$ ante todo por esa entidad llamada eufemísticamente "los mercados" (que no es otra cosa que el conjunto articulado de los voraces y desenfrenados sectores especulativos, monopolísticos e internacionalizados del capitalismo financiero parasitario), no es ese el escenario que anticipaba con toda justeza Rodrigo Facio y más aún, habrá quedado atrás la necesidad y urgencia del "programa de rectificaciones" tanto el local como el internacional? ¿Será descartable hoy su tesis de colocar en formación "por la vía de los hechos, sin dogmas ni apriorismos, una nueva concepción económica y social de carácter pragmático, realista y flexible, en donde rasgos capitalistas se mezclan con rasgos socialistas $y$ matices individualistas y liberales con matices estatistas, pero teniendo siempre por estrella de orientación el respeto a la dignidad del hombre y el mejoramiento de sus condiciones de vida"?

En el ensayo "Planificación Económica en Régimen Democrático" de 1959, insiste en el tema, que venía planteando desde los años de 1940, del programa de las rectificaciones orientado a fortalecer las bases sociales de la democracia y el humanismo socialista, pero destacando mucho más que en esa época la posibilidad de utilizar la herramienta de la planificación que "ha desbordado las rígidas fronteras de los dogmatismos económico-sociales", eso sí combinada con la descentralización y desconcentración del poder; y reafirmando que “... no existe una incompatibilidad inherente entre el principio del gobierno democrático $y$ los grandes proyectos de reconstrucción económica..." ("Planificación Económica en Régimen Democrático". Separata de la Revista de Ciencias Sociales de la UCR 4. Septiembre 1959: 24). Al final, resume su propuesta de cambios a ejecutar en cerca de una veintena de lineamientos de política económica-social que se sintetizan a continuación: establecimiento de un organismo central de planificación, señalamiento de metas u objetivos económicos, proyectos específicos de inversión con indicación de prioridades $y$ establecimiento del control democrático sobre la planificación, fortalecimiento de un claro liderazgo nacional capaz de concebir y aplicar una estrategia integral del problema del desarrollo, adopción de una política social que prepare la base humana del desarrollo, especialmente mediante políticas de educación y salud; reconocimiento jurídico y social del papel decisivo de la empresa privada, fortalecimiento de las clases medias y trabajadoras de la ciudad y el campo, preparación para llevar a cabo las inversiones básicas de la economía nacional, introducir una legislación para la atracción controlada de inversiones extranjeras, claras políticas y garantías de estabilidad monetarias; política económica internacional autónoma y flexible con arreglo a convenios internacionales de precios y controles adecuados del capitalismo internacional, y revisión y ajuste permanente de las estructuras de economía mixta.

\section{VI}

Finalmente, para cerrar esta disertación en memoria y homenaje a Rodrigo Facio, una reflexión personal, tomada de un artículo publicado en la revista Estudios Sociales Centroamericanos (Nro. 4. Enero-abril de 1973: 145-156) bajo el título "En torno al Estudio sobre Economía Costarricense de Rodrigo Facio" y la cual mantiene plena actualidad y pertinencia en este momento cuando las fuerzas del neoliberalismo se aprestan a terminar de destruir el Estado Social de Derecho para consumar el modelo del ajuste estructural salido del llamado "Consenso de Washington" y a su vez, sustituir ese Estado, finalmente, con un "Estado Liberal de Mercado", elitista, excluyente y antidemocrático bajo la fórmula autoritaria, ya proclamada orbi et urbi, de una "tiranía en democracia”. Lo cual implica, adicionalmente, el desnacionalizarlo y liquidarlo como auténtico Estado-Nación para ponerlo a funcionar como una maquinaria globalizada más al servicio de los grandes bancos, las corporaciones transnacionales $y$ los OFIs. de 1973:

He aquí el texto de aquella reflexión

Se ha confundido la indispensable modernización del país con una ampliación de los márgenes de consumo de selectos grupos urbanos, los que cada 
vez dejan más atrás a los sectores obrero-campesinos, quienes pagan con su indigencia las ganancias exorbitantes de las minorías acaparadoras. El problema de siempre, diría Rodrigo Facio. Pero no es así. Asistimos a una época que solo en sus inicios, en su etapa preparatoria, vivió el autor [del Estudio]. La dependencia externa que a él tanto preocupara se ha profundizado, absorbiendo no solo a los grupos empresariales y gerenciales privados, sino también a una burocracia estatal sin iniciativa $y$ totalmente supeditada a los planes que le vienen desde el exterior, programados y financiados [por los OFIs]. Por otra parte, los pequeños propietarios rurales han visto cómo se reducen más y más sus niveles y posibilidades de vida $y$ forman ahora una capa social miserable en constante aumento; mientras los obreros urbanos recién incorporados a la economía del consumo tendrán que esperar mucho tiempo para mejorar realmente sus condiciones de vida, a lo que sin duda aspiran incitados por la propaganda comercial...

El reformismo a cargo de diletantes políticos debe dar paso ahora a un período de reconstrucción nacional, de defensa de nuestra economía y nuestros recursos, $y$ de auténtico desarrollo social de los sectores de la población menos privilegiados. Se impone el poner fin a los efectos deformantes que, sobre la totalidad de la estructura del país, están teniendo tanto las operaciones desenfrenadas de la burguesía gerencial al servicio de intereses foráneos, como el peculado y el despilfarro burocráticos. No se trata de entrar en un período chauvinista y aislacionista. Lo que se debe buscar es un conjunto de estrategias y precisas reglas para el manejo de las relaciones internacionales estatales $y$ de consorcios privados, todo en beneficio de los más altos intereses de la sociedad costarricense y de las clases sociales que, desde el siglo pasado, vienen siendo explotadas por las minorías privilegiadas. Hay que ir al análisis de la situación actual, de las alternativas viables de acción que se ofrecen. Y diseñar una teoría que nos guíe en el proceso de transformación de la realidad nacional; en la solución de los problemas que presenta la remoción de los nexos y obstáculos que impiden el máximo aprovechamiento de los recursos y el talento de los costarricenses; $y$ sobre todo en cuanto a la organización de los sectores populares que debe acelerarse para que estos puedan luchar independientemente por sus intereses.

Rodrigo Facio tiene el indiscutible mérito de habernos señalado hace tiempo un camino, una vía de acción renovadora para el logro de una avanzada cultura nacional en donde la productividad ascendente del trabajo de los costarricenses contribuyera a la afirmación de su autonomía, al avance de la creatividad y a la remoción de las barreras clasistas que atentan contra nuestro desarrollo social integral e imponen severas restricciones a la transformación de las fuerzas productivas. Al servicio de ese ideal hizo su contribución a la historia social y económica de Costa Rica. Por todo ello es que se hace necesario retomar el análisis histórico-social y la reflexión allí donde los dejó Rodrigo Facio, volcarse de lleno hacia el estudio de las condiciones reales de nuestro subdesarrollo y nuestra dependencia, de las posibilidades de autonomía y abolición de la pobreza, la miseria y la ignorancia, utilizando para ellos los aportes de nuevos estudios y de audaces planes que exploren las alternativas del desarrollo y comprometan en la acción política.

Y terminamos diciendo en el artículo, lo que hoy deseamos reafirmar:

Solo una acción político-social orientada sobre la base del estudio de la historia y la experimentación, consciente 
asimismo de la necesidad de resguardar las mejores tradiciones nacionales y democráticas, podrá garantizarnos la reconstrucción del país y el máximo aprovechamiento de sus potencialidades. ¿Y qué es esta propuesta sino una renovación del ideario que animara a Rodrigo
Facio, un llamado para su actualización en momentos cuando la sociedad costarricense parece dejar atrás una etapa más de su evolución?

Fecha de ingreso: 03/07/2011 Fecha de aprobación: 05/08/2011 